\title{
Bizhan Aarabi and Knowledge Development in Neurotrauma
}

Zahra Ghodsi, PhD, Postdoctoral Fellow'; Shahriar Ghashghaei, MD Student'; Masoud Sohrabi Asl, MD Student'; Mohammad Hosein Ranjbar Hameghavandi, MD Student ${ }^{1}$; Hossein Rezaei Aliabadi, MSc ${ }^{2}$; Ahmad Pourrashidi, MD ${ }^{1,3}$; Mahkameh Abbaszadeh MD Student ${ }^{1}$; Seyed Mohammad Ghodsi, MD ${ }^{4^{*}}$; Vafa Rahimi-Movaghar, MD ${ }^{1,4,5,6,7,8^{*}}$

\author{
${ }^{1}$ Sina Trauma and Surgery Research Center, Tehran University of Medical Sciences, Tehran, Iran \\ ${ }^{2}$ School of Medicine, Bam University of Medical sciences, Bam, Iran \\ ${ }^{3}$ Department of Neurosurgery, Tehran University of Medical Sciences, Tehran, Iran \\ ${ }^{4}$ Brain and Spinal Cord Injury Research Center, Neuroscience Institute, Tehran University of Medical Sciences, Tehran, Iran \\ ${ }^{5}$ Department of Neurosurgery, Shariati Hospital, Tehran University of Medical Sciences, Tehran, Iran \\ ${ }^{6}$ Universal Scientific Education and Research Network (USERN), Tehran, Iran \\ ${ }^{7}$ Institute of Biochemistry and Biophysics, University of Tehran, Tehran, Iran \\ ${ }^{8}$ Visiting Professor, Spine Program, University of Toronto, Toronto, Canada
}

\begin{abstract}
Neurotrauma (NT) is one of the common causes of mortality and morbidity. Investigating the role of people who had an impact on the development of knowledge of NT is reasonable. Our aim is to investigate the role of Bizhan Aarabi, professor of Neurosurgery, on the knowledge development in NT. Accordingly, we searched the Scopus database for Bizhan Aarabi on August 8, 2020 and selected papers with at least 10 citations, investigating his impact on NT and details of his publications. He has published 168 papers including original articles, reviews, conference papers, letters, and editorials according to the Scopus databases. There are 112 papers with 10 or more citations. Thirty-eight out of 112 papers (33.9\%) were in the first and the highest rank journal: 29 in Neurosurgery and 9 in the Journal of Neurotrauma. Twenty-four papers have the level of evidence (LOE) of " 1 ". Bizhan Arabi developed knowledge in NT especially in the cervical spine/spinal cord trauma and brain injury and his publications are references for spine/neurosurgeons.

Keywords: Brain injuries, Iran, Neurosurgery, Spinal cord injuries, Traumatic

Cite this article as: Ghodsi Z, Ghashghaei S, Sohrabi Asl M, Ranjbar Hameghavandi MH, Rezaei Aliabadi H, Pourrashidi A, et al. Bizhan Aarabi and knowledge development in neurotrauma. Arch Iran Med. 2021;24(3):253-259. doi: 10.34172/aim.2021.36
\end{abstract}

Received: August 28, 2020, Accepted: September 9, 2020, ePublished: March 1, 2021

\section{Introduction}

Neurotrauma (NT) is known as a significant cause of morbidity and mortality within communities, especially in younger ages. ${ }^{1}$ Evaluation of the history of NT shows us the trace of trauma to the nervous system including the brain and spinal cord since the ancient periods. The studies on the discovered old skull bones or other parts of the body concomitant with the tinge of some treatment methods on them suggest the fact. Furthermore, manuscripts and books related to the physicians prove the challenges pertaining to NT and its treatment protocols. ${ }^{2}$ NT is an ongoing life-threatening problem occurring due to different mechanisms. As the literature shows, despite a lower rate of NT following motor vehicle accidents in developed countries compared to the developing ones, other traumas are currently prominent. In developing countries, the high rate of road traffic collisions along with other possible mechanisms result in trauma of the central nervous system. ${ }^{3}$ All the above mentioned display the paramount importance of NT in an individual's life. Therefore, it is important how we should approach and manage NT. There are many studies about this topic in the literature on developed techniques and improved treatments that are still in progress. Nowadays, we need more investigations that require an accurate research plan.

When searching in this wide field, especially in Iran, the name of Bizhan Aarabi is significant. If we want to evaluate his role in the development of knowledge of NT, we should track his works thoroughly. Reading his biography provides us with several sparkling points that could be valuable, especially for medical students and physicians. He was curious and learned medicine enthusiastically. $\mathrm{He}$ spent his neurosurgical internship at Namazi Hospital of Shiraz in 1973 under the supervision of Dr. Kazem Abbassioun, trained by Earl Walker in Johns Hopkins. In 1973, he went to the United States for a surgery internship at Cook County Hospital in Chicago, spending half of his training under the supervision of Dr. Roy Selby in

\footnotetext{
*Corresponding Author: Vafa Rahimi-Movaghar, MD; Professor of Neurosurgery, Director of Traumatic Spinal Cord Injury, NSCIR-IR Principal Investigator, Sina Trauma and Surgery Research Center, Sina Hospital, Hassan Abad Square, Imam Khomeini Avenue, Tehran, Iran. Tel: +98(216)675-7001; +98(915)342-2682; +1(226)919-8541; Fax: +98(216)675-7009; Email: V_rahimi@sina.tums.ac.ir/ v_rahimi@yahoo.com
} 
the Neurosurgery Department affiliated with the Illinois School of Medicine. After neurosurgery training under the supervision of Dr. D M Long at Johns Hopkins Hospital, he returned to Iran in July of 1979 and had a great role in the professional treatment of injured veterans in the Iraq-Iran war. ${ }^{4}$ His critical-minded personality resulted in recording all the data of the injured veterans by handwriting parallel to their treatment. Even though there was not a specific software to record them, he gathered all the data from his wounded patients. This precise approach yielded a large data bank which gave him the ability to start his impressive articles and book in the field of his interest in NT. ${ }^{4}$

Simultaneously, he completed the neurosurgery fellowship period at the Wellesley Hospital in Toronto, Canada, in 1980, and Hamilton General Hospital in Hamilton, Canada in 1981. In 1982 and 1983, the American Neurosurgery Board and the Royal College of Surgeons of Canada certified him as Diplomate of the American Board of Neurosurgery and Fellow of the Royal College of Surgeons of Canada, respectively. ${ }^{5}$ His main research interest was NT including traumatic cervical spinal cord injury (SCI) and traumatic brain injury (TBI) and one of his clinical interests was traumatic cervical central cord syndrome.

In 1990, he became a full professor and also the chairman of neurosurgery department at Shiraz University of Medical Sciences until 1995. 5 Thereafter, he went back to the United States as an associate professor at the Nebraska Medical School in the Division of Neurosurgery and performed basic animal studies in NT. He moved to the Maryland Medical School as the Director of Neurotrauma after five years. ${ }^{4}$ He has been a director of the Neurotrauma in R. Adams Cowley Shock Trauma Center of the University of Maryland Medical Center since 2000 and professor of neurosurgery from 2007 up to now. Meanwhile, he is a member in the Maryland State Ethics Commission which shows his interest in ethics. Precise and well-developed questions, literature search, study design, accurate data collection and production of a good data bank, data analysis, data interpretation, obsession in writing and publication in high impact journals are important steps which he followed to add something valuable to the literature that improved the existing knowledge. ${ }^{4}$ According to this information, introducing and evaluating a professor of neurosurgery who came back to Iran and built a framework teach us how we could do research on a correct pathway, and how we must add something new to the science. Although there are many ongoing studies in the field of trauma in Iran, in this modern era, we need more individuals like professor Aarabi to improve the level of knowledge. Therefore, our purpose was to assess the quality and quantity of publications of Bizhan Aarabi in the field of NT, especially in cervical SCI.

\section{His Scientific Contributions}

We searched Aarabi's publications in the Scopus database. The results were analyzed based on journal metrics and scientific impact to draw a conclusion on his impact on NT science. We analyzed 112 papers with $\geq 10$ citations in the Scopus database for qualitative and quantitative reports. We investigated the article subjects and their impacts on NT during the time periods. We counted the article types, journal names, and their impact factors (IFs), and the level of evidence (LOE) of each paper. The Oxford Centre for Evidence-based Medicine - Levels of Evidence was used to determine the LOE for each of the 110 articles. ${ }^{6-8}$ Data on the books and awards have different sources. Data on books are from Scopus and Aarabi's profile on the website of the University of Maryland School of Medicine. The awards were added from his profile on the website of the University of Maryland School of Medicine.

\section{Qualitative Analysis}

Seven of 112 articles pertain to the period from 1977 to 1988 and address a diverse range of topics including traumatic internal carotid artery occlusion, ${ }^{9}$ dynamics of cerebral edema, ${ }^{10}$ three case reports, ${ }^{11-13}$ enlarging optic chiasmal glioma ${ }^{14}$ and post-surgical IQ and behavior in childhood craniopharyngioma. ${ }^{15}$ The most cited case series is a study of 10 patients with symptomatic intradural extramedullary spinal metastasis treated with decompressive laminectomy. After treatment, seven became ambulatory and three remained unable to walk. ${ }^{12}$ From 1980 to 1988 which coincided with the Iraq-Iran war, he focused on war-related brain injuries to investigate the infections, vascular and epileptic complications of penetrating brain injury at the Shiraz University of Medical School. ${ }^{16-23}$ Afterward, he shifted his research to focus on traumatic SCI by means of diagnostic, prognostic, and potential treatment strategies. To begin with, novel classification systems for SCI patients were introduced: (1) AOSpine thoracolumbar spine injury and AOSpine sub-axial cervical spine injury classification systems based on three main elements consisting of morphology classification of fracture, neurological condition grading, and description of the patient modifier. ${ }^{24,25}$ (2) Subaxial cervical spine trauma classification with a total score equal to the sum of three elements consisting of the morphology of injury, the Disco-Ligamentous Complex, and neurologic state. ${ }^{26}$ By collaborating with AOSpine, the team proposed three guidelines comprising (1) An update on the first management guideline of acute cervical spine and SCI patients including recommendations on transportation and immobilization ${ }^{27}$; (2) Introduction of degenerative cervical myelopathy (DCM) practice guideline for patients suffering from a range of mild to severe stages ${ }^{28}$; and 3) Guideline for the management of acute SCI and central cord syndrome with suggestions regarding early surgery (less than 24 hours) in the mentioned patients. ${ }^{29}$ 
In addition, the same team proposed reliability analysis and injury score for classifications of thoracolumbar spine fracture. ${ }^{30,31}$ Also, the AOSpine sub-axial cervical spine injury algorithm and the AOSpine thoracolumbar spine injury algorithm are worthy of mention. The first algorithm recommends an anterior approach in case of burst or compression and a posterior or combined approach in case of translation or rotation; the second algorithm suggests two fracture types of $\mathrm{A} 2 \mathrm{~N} 0$ and $\mathrm{A} 3 \mathrm{~N} 0$ as non-operative types according to the vote of participants (total participants: 483). ${ }^{32,33}$

His focus was on NT and its two related subsections: SCI and TBI. The highest number of citations $(\mathrm{N}=$ 457) with a great impact in the field of clinical SCI was a multi-center North American cohort study, for which Bizhan Aarabi was responsible in Maryland/Baltimore. Of 182 patients with traumatic acute cervical SCI, who underwent early decompression (less than 24 hours after SCI), $19.8 \%$ experienced equal to or more than 2 grades (AIS) improvement which is 2.8 times higher than those 131 patients with late decompression (more than 24 hours after SCI). Thus, early decompression of patients with acute cervical SCI results in better neurological outcomes. ${ }^{34}$ Another study on timing of decompressive surgery in SCI patients was a 20 -question survey; $80 \%$ of the 971 participants preferred early decompression. ${ }^{35}$ Also, some of his highlighted scientific achievements are as follows: publications about the effect of decompressive craniectomy and decompressive laparotomy on intracranial pressure (ICP), the results of which show that decompressive craniectomy and decompressive laparotomy are beneficial for reduction of $\mathrm{ICP}^{36-38}$ and traumatic aneurysm following missile and penetrating head wounds and its complications. ${ }^{17,20,21}$ For instance, 255 patients with head wounds and dural penetration due to highvelocity missile injury enrolled in a study designed and performed by Aarabi to find important variables causing a traumatic false aneurysm. The findings indicated that veterans who sustained penetrating shell fragment injuries in the proximity of pterion were at higher risk for vascular injuries. ${ }^{19}$

Looking at the SCI as an unresolved medical problem, he was involved in studies on the effectiveness of methylprednisolone and GM-1 ganglioside, ${ }^{39}$ pharmacokinetics and effectiveness of riluzole, ${ }^{40-42}$ introducing five promising agents for SCI pharmacotherapy (riluzole, glyburide, magnesium sulfate, nimodipine, and minocycline $)^{43}$ and a systematic review on proper utilization of methylprednisolone sodium succinate. ${ }^{44}$ Also, a notable systematic review was conducted to assess cellular therapies in terms of current use, safety and effectiveness in traumatic SCI in humans that illustrated relatively safe cellular-mediated methods with variable degrees of neurological recovery in adults. ${ }^{45}$ In their study published in the New England Journal of Medicine in 2014 for pharmacological therapy in TBI, they showed that phlebitis or thrombophlebitis had higher occurrence in the study group. ${ }^{46}$

One of the most impressive activities of Aarabi in SCI research was his contribution to spinal column fracture classification by the AOSpine KF, the thoracolumbar Injury Classification and Severity Score (TLICS), and the Subaxial Cervical Spine Injury Classification score (SLIC) - a data-driven criterion which was developed to help in surgical decision making along with a classification system of spinal column injury. Both systems had reasonable inter- and intra-observer reliability and are used worldwide. ${ }^{24,25,32,47}$

In the field of diagnostic tools evaluation, Aarabi and colleagues proposed two magnetic resonance imaging (MRI) indices for defining surgical indication for cervical traumatic SCI: mean canal compromise and mean spinal cord compression. ${ }^{48,49}$ Related papers on prediction of neurological outcome include studies on maximum spinal cord compression, ${ }^{50,51}$ spinal cord hemorrhage, ${ }^{50}$ intramedullary hemorrhage, ${ }^{51,52}$ and cord swelling. ${ }^{50,51}$ One other outstanding study for prediction of neurological outcome using linear regression algorithm was conducted to calculate the probability of independence after 1 year of injury by using variables such as age, American Spinal Injury Association (ASIA) grade, ASIA Motor Score (AMS), and MRI signals. This study suggests that there is a direct correlation between first-year outcome and initial AIS grade and AMS while an inverse correlation was seen between outcome and age and MRI signals. ${ }^{53}$ To differentiate hemorrhagic from non-hemorrhagic SCI, he and his team proposed a diffusion tensor imaging index as a reliable reflection of the severity of the SCI. ${ }^{54}$ Considering SCI as a backbone in his research, possible non-traumatic SCI i.e. DCM would be included. He has professional experience in DCM by means of basic science and clinical papers. The result of their work on the DCM led to development of a guideline based on the systematic review for DCM management. ${ }^{28}$

Coinciding with the Iraq-Iran war, Aarabi's research focused on TBI. This began with urgent therapeutic interventions for penetrating TBI (i.e. missiles) and was followed by evaluating more sophisticated diagnostic and prognostic biomarkers in this field. When there was no data registry for Iranian soldiers during the Iraq-Iran war, he began a comprehensive work on different aspects of penetrating TBI and its consequences. Their work on the field of TBI led to an evidence-based approach to the rescue surgical interventions, ${ }^{36-38}$ diagnostic and therapeutic approaches to vascular injury, ${ }^{55-59}$ and also infectious complications ${ }^{17}$ following penetrating TBI. They showed that the Glasgow Coma Scale (GCS) and Extended Glasgow Outcome Score (GOSE) are two outcome predictors in patients suffering TBI. ${ }^{16,60}$

In the second paper based on the highest number of 
citations $(\mathrm{N}=405)$, Aarabi et al showed that in 20 out of 50 patients $(40 \%)$ of TBI with severe (malignant) brain edema, craniectomy of the frontotemporoparietal bone (median anteroposterior of $15 \mathrm{~cm}$ ) and then dural opening and duraplasty not only could save their life and improved their ICP, also 20 out of 50 patients saved and had good outcome. Therefore, in refractory high ICP, decompressive craniectomy was associated with a better-than-expected functional outcome. ${ }^{36}$

Based on his extensive work on missile injury to the head, he wrote a book entitled "Missile Injuries of the Head and Neck". ${ }^{5}$ Aarabi et al performed a systematic study on war wounds to determine the actual incidence of traumatic brain aneurysm caused by a missile. ${ }^{19}$ They used digital subtraction angiography and new CT scanbased diagnostic criteria (modified Denver criteria) ${ }^{61}$ for this purpose. When different biomarkers were proposed in the literature as potential diagnostic and prognostic tools in TBI in recent decades, they dedicated their own power and facilities to explore the field as a new era in the TBI study. ${ }^{58}$

\section{Quantitative Analysis}

One hundred and twelve of his articles have each been cited $\geq 10$ times in the Scopus database up until the date of our search, August 8, 2020. Thirty-eight out of 112 papers $(33.9 \%)$ were in the first and the highest rank journal of Neurosurgery and NT -29 in Neurosurgery and 9 in the Journal of Neurotrauma. Twenty-four papers have the LOE of " 1 ". The most common study types were guidelines (17\%), cohorts (16\%), and review articles (16\%). Furthermore, the number of case reports has decreased over time and the number of clinical guidelines, systematic review, and review articles has increased.

One hundred ten of 112 articles had defined LOE (the other two are animal studies). Among 110 articles, 71 studies on Spine trauma and 27 studies on Brain trauma indicate the two most prevalent subjects for his research. Based on the Scopus database, the median number of citations of all the articles (which were cited at least 10 times) was 60.4 with a median journal IF of 3.08. The most citations were 1526 and 1076, pertaining to the Neurosurgery journal and Spine journal, respectively. Fifty $(44.2 \%)$ articles of the selected ones are in the top 10 neurosurgical journals. ${ }^{62,63}$ Of 112 papers, 110 studies had defined LOE and 2 were animal studies. The different study titles described in the qualitative section have different LOEs. Papers on the subject of spinal trauma and brain trauma had the highest LOE (I).

\section{Books}

Dr. Aarabi has published the following four books:

1. An introduction to the treatment of craniocerebral battle wounds. Bizhan Aarabi (ed). Office of the Vice-Chancellor for Research. Shiraz University
Press, $1987 . .^{5}$

2. Beyond Coma: Brain Death. Bizhan Aarabi (ed). Parvaz Press, Shiraz, Iran, 1993. ${ }^{5}$

3. Missile Injuries of the Head and Neck. Bizhan Aarabi and Howard Kaufman (eds). American Association of Neurological Surgeons Publications Office, New Hampshire, $1999 .{ }^{64}$

4. Decompressive Craniectomy. Bizhan Aarabi et al. Nova Science Publishers, New York, 2018. ${ }^{65}$

\section{Books, Awards and Honors}

His publications consist of four books. ${ }^{5,64,65}$ There are many more book chapters. ${ }^{5,63,66,67}$ In 1973, he not only became a Valedictorian at Pahlavi University Medical School but also got the Highest Achievement Award from the Shiraz University Medical School. In 1987, he won the First Prize Award for "Traumatic aneurysms due to missile head wounds", and in 1990, the Iranian government awarded him the Medal of Honor and Achievement. He also won the Hero Award five times from the R. Adams Cowley Shock Trauma Center in 2001-2004, 2006, 2007, and 2010.5 His two recent awards include the International Impact Award, National Spinal Cord/column registry of Iran (NSCIR-IR), and Endowed Neurotrauma Professorship Chair Award UMSOM (University of Maryland School of Medicine), both of which were awarded in 2018.5 Bizhan Aarabi focused on research on NT, especially traumatic cervical SCI and TBI. The five characteristics of his papers and books are based on his good thinking and preparation of well-organized questions; precise data collection even in the emergency and conflicts; insistence on completing the study; ethical concerns; collaboration and teamwork not only internally and inside his institute, but also internationally and multi-institutionally. Therefore, his publications are high-quality and published in the first rank neurosurgery/neurotrauma journals.

We emphasized his role not only in NT but also in his few scientific papers in neurosurgery not related to NT. We did not consider any other aspects and dimensions of Bizhan Aarabi not only as a human, physician, teacher, mentor, father, and surgeon but also even in research. We could not show his precision and obsession in his ethical concerns and his persistence and teamwork. Aarabi is a multi-dimensional man which includes his specific considerations in the development of the department of neurosurgery in Shiraz University of Medical Sciences which might be the best in the south of Iran or, at least in some aspects, even the best in the country. One of the specificities of his department is after a quarter of a century of his move to the US, those who well educated and trained by him and his successors produced the only subspecialty department of Neurosurgery in the country which consists of different specific sections and perform education, research, and treatment specifically. His specific role as a precise surgeon and operations in the 
United States and Iran is another issue. His center in the south of Iran was a referral center even for Arabic countries for surgery and consultations. He had a valuable role as a father and as a husband.

We did not consider anything about his family and the role of his Iranian American wife who is a head nurse of the intensive care unit of the department of neurosurgery. In this manuscript, we only focused on some quantitative points that are related to scientometric aspects and a few qualitative issues. Finally, we believe that any publication in top journals of "Neurosurgery" and "J Neurotrauma" is valuable even with fewer than 10 citations. On the other hand, most recent publications need time to be cited. We did not include them because of the predefined citation threshold. This study introduced Bizhan Arabi as a successful Neurosurgery/Neurotrauma scientist based on his high quality and frequent papers with the best LOE, high-citation papers, and his teamwork in AOSpine KF/ SCI. He is a reference for science and literature in the subject of the cervical spine/spinal cord trauma and brain injury for spine and neurosurgeons.

\section{Conflict of Interest Disclosures \\ None.}

\section{Ethical Statement}

The Ethics Committee of Tehran University of Medical Sciences approved the study, and the reference number is IR.TUMS.VCR. REC.1398.796.

\section{Funding}

This work was funded by Tehran University of Medical Sciences, (Grant No. 98-02-38-41414).

\section{References}

1. Graham D, McIntosh T, Maxwell W, Nicoll J. Recent advances in neurotrauma. J Neuropathol Exp Neurol. 2000;59(8):64151. doi: 10.1093/jnen/59.8.641

2. Di leva A, Gaetani P, Matula C, Sherif C, Skopec M, Tschabitscher M. Berengario da Carpi: a pioneer in neurotraumatology: Historical vignette. J Neurosurg. 2011;114(5):1461-70. doi: 10.3171/2010.10.JNS101331.

3. Reilly P. The impact of neurotrauma on society: an international perspective. Prog Brain Res. 2007;161:3-9. doi: 10.1016/ S0079-6123(06)61001-7.

4. Azizi MH. History of Shiraz faculty of medicine: in honor of Dr. Bizhan Arabi (Fifth book). Tehran: Mirmah; 2019. 19-34 p.

5. University of Maryland School of Medicine. Faculty Profiles: Bizhan Aarabi, MD 2020 April. Available from: https://www. medschool.umaryland.edu/profiles/Aarabi-Bizhan/.

6. Howick J, I Chalmers, P Glasziou, T Greenhalgh, C Heneghan, A Liberati, I Moschetti, B Phillips, H Thornton, and O Goddard. The Oxford 2011 Levels of Evidence: Ocebm Levels of Evidence Working Group. Oxford Centre for EvidenceBased Medicine, Oxford; 2011. Available from: http://www. cebm.net/index.aspx?o=5653.

7. Howick J. The Oxford 2011 Levels of Evidence. 2011. Available from: http://www.cebm.net/index.aspx?o=5653.

8. Howick J, lain Chalmers, Paul Glasziou, Trish Greenhalgh, Carl Heneghan, Alessandro Liberati, Ivan Moschetti, Bob Phillips, and Hazel Thornton. "The 2011 Oxford Cebm Evidence Levels of Evidence (Introductory Document). Oxford Center for Evidence Based Medicine; 2011. Available from: https:// www.cebm.net/2011/06/2011-oxford-cebm-levels-evidence- introductory-document/.

9. Aarabi B, McQueen J. Traumatic internal carotid occlusion at the base of the skull. Surg Neurol. 1978;10(4):233-6.

10. Aarabi B, Long DM. Dynamics of cerebral edema: The role of an intact vascular bed in the production and propagation of vasogenic brain edema. J Neurosurg. 1979;51(6):779-84. doi: 10.3171/jns.1979.51.6.0779.

11. Aarabi B, Pasternak G, Hurko O, Long DM. Familial intradural arachnoid cysts: report of two cases. J Neurosurg. 1979;50(6):826-9. doi: 10.3171/jns.1979.50.6.0826.

12. Perrin RG, Livingston KE, Aarabi B. Intradural extramedullary spinal metastasis: a report of 10 cases. J Neurosurg. 1982;56(6):835-7. doi: 10.3171/jns.1982.56.6.0835

13. Aarabi B, Chambers J. Giant thrombosed aneurysm associated with an arteriovenous malformation: case report. J Neurosurg. 1978;49(2):278-82. doi: 10.3171/jns.1978.49.2.0278.

14. Aarabi B, Long D, Miller NR. Enlarging optic chiasmal glioma with stable visual acuity. Surg Neurol. 1978;10(3):175-7.

15. Clopper RR, Meyer III WJ, Udvarhelyi GB, Money J, Aarabi B, Mulvihill JJ, et al. Postsurgical IQ and behavioral data on twenty patients with a history of childhood craniopharyngioma. Psychoneuroendocrinology. 1977;2(4):365-72. doi: 10.1016/0306-4530(77)90006-3.

16. Aarabi B. Surgical outcome in 435 patients who sustained missile head wounds during the Iran-Iraq war. Neurosurgery. 1990;27(5):692-5.

17. Aarabi B. Causes of infections in penetrating head wounds in the Iran-Iraq War. Neurosurgery. 1989;25(6):923-6. doi: 10.1097/00006123-198912000-00011.

18. Aarabi B, Alibaii E, Taghipur M, Kamgarpur A. Comparative study of functional recovery for surgically explored and conservatively managed spinal cord missile injuries. Neurosurgery. 1996;39(6):1133-40. doi: 10.1097/00006123199612000-00013.

19. Aarabi B. Traumatic aneurysms of brain due to high velocity missile head wounds. Neurosurgery. 1988;22(6 Pt 1):1056-63. doi: 10.1227/00006123-198806010-00014.

20. Aarabi B. Comparative study of bacteriological contamination between primary and secondary exploration of missile head wounds. Neurosurgery. 1987;20(4):610-6. doi: 10.1227/00006123-198704000-00018.

21. Aarabi B. Management of traumatic aneurysms caused by high-velocity missile head wounds. Neurosurg Clin N Am. 1995;6(4):775-97.

22. Aarabi B, Haghshenas M, Rakeii V. Visual failure caused by suprasellar extramedullary hematopoiesis in beta thalassemia: case report. Neurosurgery. 1998;42(4):922-5. doi: 10.1097/00006123-199804000-00134.

23. Aarabi B, Taghipour M, Haghnegahdar A, Farokhi M, Mobley L. Prognostic factors in the occurrence of posttraumatic epilepsy after penetrating head injury suffered during military service. Neurosurg Focus. 2000;8(1):e1. doi: 10.3171/ foc.2000.8.1.155.

24. Vaccaro AR, Oner C, Kepler CK, Dvorak M, Schnake K, Bellabarba $\mathrm{C}$, et al. AOSpine thoracolumbar spine injury classification system: fracture description, neurological status, and key modifiers. Spine (Phila Pa 1976). 2013;38(23):202837. doi: 10.1097/BRS.0b013e3182a8a381.

25. Vaccaro AR, Koerner JD, Radcliff KE, Oner FC, Reinhold M, Schnake KJ, et al. AOSpine subaxial cervical spine injury classification system. Eur Spine J. 2016;25(7):2173-84. doi: 10.1007/s00586-015-3831-3.

26. Vaccaro AR, Hulbert RJ, Patel AA, Fisher C, Dvorak M, Lehman Jr RA, et al. The subaxial cervical spine injury classification system: a novel approach to recognize the importance of morphology, neurology, and integrity of the disco-ligamentous complex. Spine (Phila Pa 1976). 2007;32(21):2365-74. doi: 10.1097/BRS.0b013e3181557b92. 
27. Walters BC, Hadley MN, Hurlbert RJ, Aarabi B, Dhall SS, Gelb DE, et al. Guidelines for the management of acute cervical spine and spinal cord injuries: 2013 update. Neurosurgery. 2013;60(CN_suppl_1):82-91. doi: 10.1227/01. neu.0000430319.32247.7f.

28. Fehlings MG, Tetreault LA, Riew KD, Middleton JW, Aarabi B, Arnold PM, et al. A clinical practice guideline for the management of patients with degenerative cervical myelopathy: recommendations for patients with mild, moderate, and severe disease and nonmyelopathic patients with evidence of cord compression. Global Spine J. 2017;7(3 Suppl):70S-83S. doi: 10.1177/2192568217701914.

29. Fehlings MG, Tetreault LA, Wilson JR, Aarabi B, Anderson P, Arnold PM, et al. A Clinical Practice Guideline for the Management of Patients With Acute Spinal Cord Injury and Central Cord Syndrome: Recommendations on the Timing ( $\leq 24$ Hours Versus \&gt;24 Hours) of Decompressive Surgery. Global Spine J. 2017;7(3 Suppl):195S-202S. doi: $10.1177 / 2192568217706367$.

30. Kepler CK, Vaccaro AR, Koerner JD, Dvorak MF, Kandziora F, Rajasekaran S, et al. Reliability analysis of the AOSpine thoracolumbar spine injury classification system by a worldwide group of naïve spinal surgeons. Eur Spine J. 2016;25(4):1082-6. doi: 10.1007/s00586-015-3765-9.

31. Kepler CK, Vaccaro AR, Schroeder GD, Koerner JD, Vialle LR, Aarabi B, et al. The thoracolumbar AOSpine injury score. Global Spine J. 2016;6(4):329-34. doi: 10.1055/s-00351563610.

32. Dvorak MF, Fisher CG, Fehlings MG, Rampersaud YR, Öner FC, Aarabi B, et al. The surgical approach to subaxial cervical spine injuries: an evidence-based algorithm based on the SLIC classification system. Spine (Phila Pa 1976). 2008;33(19):2124; author reply 2124-5. doi: 10.1097/BRS.0b013e31817e30e7.

33. Vaccaro AR, Schroeder GD, Kepler CK, Cumhur Oner F, Vialle LR, Kandziora F, et al. The surgical algorithm for the AOSpine thoracolumbar spine injury classification system. Eur Spine J. 2016;25(4):1087-94. doi: 10.1007/s00586-015-3982-2.

34. Fehlings MG, Vaccaro A, Wilson JR, Singh A, Cadotte DW, Harrop JS, et al. Early versus delayed decompression for traumatic cervical spinal cord injury: results of the Surgical Timing in Acute Spinal Cord Injury Study (STASCIS). PLoS One. 2012;7(2):e32037. doi: 10.1371/journal.pone.0032037

35. Fehlings MG, Rabin D, Sears W, Cadotte DW, Aarabi B. Current practice in the timing of surgical intervention in spinal cord injury. Spine (Phila Pa 1976). 2010;35(21 Suppl):S166-73. doi: 10.1097/BRS.0b013e3181f386f6.

36. Aarabi B, Hesdorffer DC, Ahn ES, Aresco C, Scalea TM, Eisenberg HM. Outcome following decompressive craniectomy for malignant swelling due to severe head injury. J Neurosurg. 2006;104(4):469-79. doi: 10.3171/ jns.2006.104.4.469.

37. D'Andrea KJ, Dutton RP, Aarabi B, Scalea TM. Decompressive laparotomy to treat intractable intracranial hypertension after traumatic brain injury. J Trauma. 2004;57(4):687-93; discussion 693-5.

38. Scalea TM, Bochicchio GV, Habashi N, McCunn M, Shih D, McQuillan K, et al. Increased intra-abdominal, intrathoracic, and intracranial pressure after severe brain injury: multiple compartment syndrome. J Trauma. 2007;62(3):647-56; discussion 656. doi: 10.1097/TA.0b013e31802ee542.

39. Hurlbert RJ, Hadley MN, Walters BC, Aarabi B, Dhall SS, Gelb $\mathrm{DE}$, et al. Pharmacological therapy for acute spinal cord injury. Neurosurgery. 2015;76 Suppl 1:S71-83. doi: 10.1227/01. neu.0000462080.04196.f7.

40. Grossman RG, Fehlings MG, Frankowski RF, Burau KD, Chow DS, Tator $\mathrm{C}$, et al. A prospective, multicenter, phase I matched-comparison group trial of safety, pharmacokinetics, and preliminary efficacy of riluzole in patients with traumatic spinal cord injury. J Neurotrauma. 2014;31(3):239-55. doi: 10.1089/neu.2013.2969.

41. Fehlings MG, Wilson JR, Frankowski RF, Toups EG, Aarabi B, Harrop JS, et al. Riluzole for the treatment of acute traumatic spinal cord injury: rationale for and design of the NACTN Phase I clinical trial. J Neurosurg Spine. 2012;17(1 Suppl):151-6. doi: 10.3171/2012.4.AOSPINE1259

42. Aarabi B, Simard JM, Kufera JA, Alexander M, Zacherl KM, Mirvis SE, et al. Intramedullary lesion expansion on magnetic resonance imaging in patients with motor complete cervical spinal cord injury. J Neurosurg Spine. 2012;17(3):243-50. doi: 10.3171/2012.6.SPINE12122.

43. Tator $\mathrm{CH}$, Hashimoto $\mathrm{R}$, Raich $\mathrm{A}$, Norvell D, Fehlings MG, Harrop JS, et al. Translational potential of preclinical trials of neuroprotection through pharmacotherapy for spinal cord injury. J Neurosurg Spine. 2012;17(1 Suppl):157-229. doi: 10.3171/2012.5.AOSPINE12116.

44. Fehlings MG, Wilson JR, Tetreault LA, Aarabi B, Anderson $\mathrm{P}$, Arnold PM, et al. A clinical practice guideline for the management of patients with acute spinal cord injury: recommendations on the use of methylprednisolone sodium succinate. Global Spine J. 2017;7(3 Suppl):203S-211S. doi: $10.1177 / 2192568217703085$.

45. Harrop JS, Hashimoto R, Norvell D, Raich A, Aarabi B, Grossman RG, et al. Evaluation of clinical experience using cell-based therapies in patients with spinal cord injury: a systematic review. J Neurosurg Spine. 2012;17(1 Suppl):230-46. doi: 10.3171/2012.5.AOSPINE12115.

46. Wright DW, Yeatts SD, Silbergleit R, Palesch YY, Hertzberg VS, Frankel $\mathrm{M}$, et al. Very early administration of progesterone for acute traumatic brain injury. N Engl J Med. 2014;371(26):245766. doi: 10.1056/NEJMoa1404304.

47. Anderson PA, Moore TA, Davis KW, Molinari RW, Resnick DK, Vaccaro AR, et al. Cervical spine injury severity score: assessment of reliability. J Bone Joint Surg Am. 2007;89(5):1057-65. doi: 10.2106/JBJS.F.00684.

48. Fehlings MG, Furlan JC, Massicotte EM, Arnold P, Aarabi B, Harrop J, et al. Interobserver and intraobserver reliability of maximum canal compromise and spinal cord compression for evaluation of acute traumatic cervical spinal cord injury. Spine (Phila Pa 1976). 2006;31(15):1719-25. doi: 10.1097/01. brs.0000224164.43912.e6.

49. Furlan JC, Fehlings MG, Massicotte EM, Aarabi B, Vaccaro $\mathrm{AR}$, Bono CM, et al. A quantitative and reproducible method to assess cord compression and canal stenosis after cervical spine trauma: a study of interrater and intrarater reliability. Spine (Phila Pa 1976). 2007;32(19):2083-91. doi: 10.1097/ BRS.0b013e318145a91c.

50. Miyanji F, Furlan JC, Aarabi B, Arnold PM, Fehlings MG. Acute cervical traumatic spinal cord injury: MR imaging findings correlated with neurologic outcome-prospective study with 100 consecutive patients. Radiology. 2007;243(3):820-7. doi: 10.1148/radiol.2433060583.

51. Kurpad S, Martin AR, Tetreault LA, Fischer DJ, Skelly AC, Mikulis $\mathrm{D}$, et al. Impact of baseline magnetic resonance imaging on neurologic, functional, and safety outcomes in patients with acute traumatic spinal cord injury. Global Spine J. 2017;7(3 Suppl):151S-174S. doi: 10.1177/2192568217703666

52. Aarabi B, Sansur CA, Ibrahimi DM, Simard JM, Hersh DS, Le E, et al. Intramedullary lesion length on postoperative magnetic resonance imaging is a strong predictor of ASIA impairment scale grade conversion following decompressive surgery in cervical spinal cord injury. Neurosurgery. 2017;80(4):610620. doi: 10.1093/neuros/nyw053.

53. Wilson JR, Grossman RG, Frankowski RF, Kiss A, Davis AM, Kulkarni $A V$, et al. A clinical prediction model for longterm functional outcome after traumatic spinal cord injury based on acute clinical and imaging factors. J Neurotrauma. 
2012;29(13):2263-71. doi: 10.1089/neu.2012.2417.

54. Cheran S, Shanmuganathan K, Zhuo J, Mirvis SE, Aarabi $B$, Alexander MT, et al. Correlation of MR diffusion tensor imaging parameters with ASIA motor scores in hemorrhagic and nonhemorrhagic acute spinal cord injury. J Neurotrauma. 2011;28(9):1881-92. doi: 10.1089/neu.2010.1741.

55. Brenner M, Stein DM, Hu PF, Aarabi B, Sheth K, Scalea TM. Traditional systolic blood pressure targets underestimate hypotension-induced secondary brain injury. J Trauma Acute Care Surg. 2012;72(5):1135-9. doi: 10.1097/ TA.0b013e31824af90b.

56. Grossman RG, Frankowski RF, Burau KD, Toups EG, Crommett JW, Johnson MM, et al. Incidence and severity of acute complications after spinal cord injury. J Neurosurg Spine. 2012;17(1 Suppl):119-28. doi: 10.3171/2012.5. AOSPINE12127.

57. Stein DM, Hu PF, Brenner M, Sheth KN, Liu KH, Xiong W, et al. Brief episodes of intracranial hypertension and cerebral hypoperfusion are associated with poor functional outcome after severe traumatic brain injury. J Trauma. 2011;71(2):36473. doi: 10.1097/TA.0b013e31822820da.

58. Stein DM, Kufera JA, Lindell A, Murdock KR, Menaker J, Bochicchio GV, et al. Association of CSF biomarkers and secondary insults following severe traumatic brain injury. Neurocrit Care. 2011;14(2):200-7. doi: 10.1007/s12028-0109496-1.

59. Stein DM, Lindell A, Murdock KR, Kufera JA, Menaker J, Keledjian K, et al. Relationship of serum and cerebrospinal fluid biomarkers with intracranial hypertension and cerebral hypoperfusion after severe traumatic brain injury. J Trauma. 2011;70(5):1096-103. doi: 10.1097/TA.0b013e318216930d.

60. Stein DM, Hu PF, Brenner M, Sheth KN, Liu KH, Xiong W, et al. Brief episodes of intracranial hypertension and cerebral hypoperfusion are associated with poor functional outcome after severe traumatic brain injury. J Trauma. 2011;71(2):36473. doi: 10.1097/TA.0b013e31822820da.

61. Harrigan MR, Hadley MN, Dhall SS, Walters BC, Aarabi B, Gelb $\mathrm{DE}$, et al. Management of vertebral artery injuries following non-penetrating cervical trauma. Neurosurgery. 2013;72 Suppl 2:234-43. doi: 10.1227/NEU.0b013e31827765f5.

62. Neurosurgery Top publications google scholar; 2020 April. Available from: https://scholar.google.com/citations?view_ op=top_venues \&hl=en \&vq=med_neurosurgery.

63. Poe RH, Reisman JL, Rodenhouse TG. Pulmonary edema in cervical spinal cord injury. J Trauma. 1978;18:71-3.

64. Aarabi B, Kaufman HH, Committee AP. Missile Wounds of the Head and Neck: American Association of Neurological Surgeons; 1999.

65. AarabiB, WessellA, PrattN, ChryssikosT, ScarboroM, Lomangino CD, et al. The Prognostic Value of Traumatic Brainstem Injury on Magnetic Resonance Imaging: A Systematic Review. 2018. In: Decompressive Craniectomy [Internet]. New York: Nova Science Publishers Surgery - Procedures, Complications, and Results. Available from: https://novapublishers.com/wpcontent/uploads/2018/11/978-1-53613-180-2_ch21.pdf.

66. Ahn E, Chiu WC, Wintermark M, Aarabi B, Eisenberg $\mathrm{H}$. Minimally invasive procedures in traumatic brain injury. In: Minimally Invasive Neurosurgery [Internet]. Humana Press; 2005. Available from: https://doi.org/10.1385/1-59259-8994:401.

67. Bizhan A, Mossop C, Aarabi JA. Surgical management of civilian gunshot wounds to the head. In: Handbook of Clinical Neurology [Internet]. Amsterdam: Elsevier Traumatic Brain Injury, Part I; 2015. p. 181-93. doi: 10.1016/B978-0-44452892-6.00012-X 